\title{
Recurrent Fibrosarcoma
}

National Cancer Institute

\section{Source}

National Cancer Institute. Recurrent Fibrosarcoma. NCI Thesaurus. Code C158428.

The reemergence of fibrosarcoma after a period of remission. 